Ismail, M. and Hussein, S. (Accepted) Long-Term Care Policies in the Gulf Region: A Case

Study of Oman. Journal of Aging and Social Policy. Date of acceptance 27/3/18

\title{
Population Aging and Long-Term Care Policies in the Gulf Region: A Case Study of Oman
}

\author{
Mohamed Ismail, MEng MComp MSc \\ Director \\ Analytical Research Ltd \\ Station House, \\ Connaught Road, \\ Surrey, GU24 0ER \\ mohamed@analyticalresearch.co.uk
}

Dr Shereen Hussein BSc, MSc, PhD

Research Professor

Social Care Workforce Research Unit

King's College London

Strand

London, WC2R 2LS

Corresponding author: Shereen.hussein@kcl.ac.uk

\section{Acknowledgment and Disclaimer}

This work partially draws on filed work conducted by the authors in Oman, which was funded by the United Nations International Children's Emergency Fund (UNICEF; Funding no. 43178811). The views presented in this analysis are those of the authors alone and do not necessarily represent those of the UNICEF or the Omani government.

\section{Conflict of Interest:}

Dr Shereen Hussein declares that she has no conflict of interest. Mr Mohamed Ismail declares that he has no conflict of interest.

\section{Authors Biographies:}

Mohamed Ismail, MEng, MComp, MSc, is the Director of Analytical Research Ltd. an independent research organisation specialised in quantitative modelling and research for the public and private sectors. He has extensive experience in quantitative methodologies and their applications in the financial sector and social science.

Dr Shereen Hussein is a Principal Research Fellow (Chair) at King's College London. She is a demographer with interest in the sociology of family and ageing. She has worked with the United Nations, the Population Council, the World Bank, UNICEF and the League of Arab States on research related to care for older people, family formation, multiple roles of women, women labor-participation and decision making within the family. Over the past decade, she has worked extensively in the fields of ageing and formal long-term care (LTC) with a research focus on complementary roles of formal and informal care. 


\title{
Population Aging and Long-Term Care Policies in the Gulf Region: A Case Study of Oman
}

Mohamed Ismail and Shereen Hussein

\begin{abstract}
Population aging is a phenomena occurring across the globe including in countries traditionally exhibiting population dividends and 'youth bulges'. The Gulf Corporation Council countries are no exception as they currently experience a process of population aging, albeit being at a different stage from many developed countries. However, due to historical high fertility rates and fast paced epidemiological transition, some of these countries will experience population aging at a higher pace than what has been observed in Europe and the United States. This article reviews recent developments in long-term care policies in the Gulf region with a focus on Oman as an example of a high-income Arab country that is experiencing population aging while still governed by traditional family agedcare norms. Utilizing existing data and published research complemented by policy analysis and field visits, we analyze the process of population ageing in Oman and neighboring countries and its policy implications.
\end{abstract}

Keywords: Arab; formal care; financing long-term care; population aging; mixed-methods

\section{Introduction}

Oman is a high-income monarchy located in West Asia and occupies the south-east of the Arab Peninsula with a population of 4.1 millions (2.5 million Omani nationals), and has a rapid population growth rate of three percent. It is one of the six countries constituting the Gulf Cooperation Council (GCC) ${ }^{1}$ organization, which was established in 1981. Growth Domestic Product (GDP) per capita has grown consistently in Oman at an average rate of seven percent per year over the period 2000-2014 combined by improvements in a number of social indicators such as women's participation in the labour market (raising from 7\% percent to $23 \%$ between 2003 and 2010), positive developments in human capital, and to some extent, improvements in social protection, health and wellbeing indicators (Al-Kandari \& Crews, 2014; Jarallah \& Al-Shammari, 1999).

Similar to most of Arab countries, Oman has been undergoing considerable demographic and socio-economic changes. The latter include changes in family structures, migration, urbanization, social forces and aging populations (Khan, Hussein \& Deane, 2017). While Oman, along with most of the GCC countries, is currently enjoying demographic dividends, reflected in large cohorts of people at the labour market participation ages, it is also experiencing a parallel process of population aging. With the observed trends of reduced fertility and mortality rates, Oman is experiencing an age-structural transition towards larger proportions of working-age populations (15-64) and older people (65+) (ESCWA, 2016).

Population aging entails an increase in the demand for Long-Term Care (LTC), defined as a set of activities and services at the intersection of state, market and family that aims to meet the health and social needs of older people. There are two main (often parallel) systems of LTC in the region: 1) informal care providers, such as unpaid family members and paid home care workers employed by the family and 2) formal care providers, such as nursing aides and support workers employed by regulated bodies (Hussein \& Ismail, 2017). The literature shows that most of the care to older people, and people with disabilities or long-term conditions, in the Arab region is provided by family members, mainly women, or 
by other informal caregivers through family and intergenerational support traditions (Hussein, 2009; Rugh, 1997; Yount \& Rashad, 2008). Such intergenerational support traditions are guided by 'unspoken' religious moral codes that emphasize the respect of older people within the family and set certain expectations and care exchange duties across generations, including grand-parenting and financial support from older to younger generations (Olmsted, 2011). Within such context, LTC support for older people has traditionally been viewed by policymakers in the region as a family matter that is woven into the texture of society. This assumption continues to persevere despite clear changes in the family structure and evidence of increased uptake of formal LTC when it becomes available.

There is a lack of accurate published statistics and research on the role of women in the provision of LTC in the region and particularly Oman. Current research evidence points to multiple responsibilities on women (daughters and daughters-in-law) including informal LTC provision at home and at time of hospitalization of older people (Ahmed \& Abbas, 1993; Hussein, 2009). There is very limited information on the age structure of informal caregivers, however, given the low median age at marriage and childbearing of current older people in the region, it is expected that daughters and daughters-in-law of older people who are 65 years or older to be in the age range of 40-55 years (Hussein, 2009). This is the age group that most frequently juggles multiple care responsibilities for children, parents and spouse or partner with age-related health problems. A study from Lebanon identifies negative impacts of LTC giving on the physical and mental health of family caregivers who are typically middle-aged married daughters (Seoud et al., 2007).

The traditional vital role of intergenerational support in meeting older people LTC needs have inspired social and health oriented laws and policies in many countries in the region. Various recent policies in the region place a clear emphasis on intergenerational solidarity - defined as the mutual exchange of resources and support among family members of different generations - as a core principle within the provision of LTC for older people including Oman's latest Social Development Strategy (2016-2025). This is in line with the 'Arab Plan of Action on Ageing' (2002-2012), which endorsed intergenerational solidarity as a key component of social development and urged States to "develop initiatives to strengthen continuous intergenerational exchange and train young people in activities aimed at benefiting older persons" and promote "intergenerational reciprocity and exchange" (Cited in Sibai, Rizk \& Kronfol,, 2014; p.48). Currently, Oman's laws and policies holding kin responsible for an older relative who is in need of LTC are under review. While the role of family is emphasized, there are other shifts in the demographic and socio-economic structures of most Arab countries that directly and indirectly challenge such assumed availability of informal support and intergenerational solidarity systems. Some of these changes include dynamic processes of urbanization and migration as well as changes in the family formation process including increased median age at marriage, increased rates of divorce and coresidency patterns (Drysdale, 2010). Furthermore, more women, who are usually the primary care providers in the region, are pursuing high levels of educations and labour market participation. Within such dynamic changes, the viability and sustainability of this aged-care model are challenged to a great extent and call for alternative and complementing approaches (ESCWA, 2018).

The Current article investigates the stage and process of population aging in the Gulf region and critically analyzes recent developments in LTC policies in Oman as an example of an oil-rich Gulf country with higher resources than most of the region. The article is divided 
into three further sections; the first details the data and methods of analyses; section two presents the findings followed by discussion in section three.

\section{Data and Methods}

The analyses presented here are based on four main data sources: 1) published statistics and indicators of LTC and aging; 2) a scoping review of the literature; 3) a review of Omani policy documents on aging, health and LTC for older people; and 4) primary data collected through workshops and discussions with Oman's MoSD and Ministry of Health $(\mathrm{MoH})$ personnel. The project was partially funded by (to be inserted after the review).

1) Published Statistics: Statistics and indicators on aging and LTC were extracted from development and demographic databases published by various international bodies such as the World Health Organisation (WHO) World Bank (WB) and the United Nations (UN). To situate the experience of Oman relative to the wider context of the region, various indicators were comparatively analyzed either for the 22 Arab countries (as identified by the League of Arab States) $)^{2}$ or for the six GCC countries. As part of the comparative statistical analysis, we categorized all Arabic countries according to their investment in health and LTC -using health expenditure per capita as a proxy- and improved life expectancy. This categorization employed a finite-mixture clustering model assuming the data to be arising from hidden subgroups that could be modeled using a finite mixture of probabilistic components (Fraley \& Raftery, 2002). The clustering procedure quantified the uncertainty through assigning probabilities to each observation to subgroup classification. Based on this model, the 22 Arab countries were classified into three groups in relation to investments in health and LTC and average life expectancy. The results of the model were visualized to represent the distributions' projections through ellipses, the smaller the ellipse, the less the uncertainty in the classification. Descriptive analysis and the finite mixture model were implemented using R statistical environment (R Core Team, 2017).

2) A scoping review of the literature entailed extensive searches of several social science databases including AgeInfo, the Social Science Research Network (SSRN), Applied Social Science Index and Abstracts (ASSIA); Health Management Information Consortium Database (HMIC); Social Care Online (SCO); and Sociological Abstracts and Social Services Abstracts (SSA/SA) covering the period from 1995-2014. Systematic search terms were used to extract articles, including: informal care, formal care, institutional care, older people, ageing/aging, policy, Arab, Gulf, Middle East and North Africa (MENA) and middle East, and each of the 22 Arab countries' names in separate searches. The initial search identified a total of 33 publications for initial inspection. The abstracts of these were read and only 15 publications were judged to be relevant to the aims of this article. The full text of these 15 publications were retrieved and analyzed. There was an over-representation of studies concerning older people from Lebanon and Egypt, with only four publications with a focus on the GCC region (Three from Kuwait and one from Saudi Arabia).

3) Omani policy review was based on reviewing key national policy documents provided by the MoSD, the MoH and the Omani Statistical Department. These were written in Arabic and were made available to the researchers by the MoSD. The review focused on pension and welfare systems that are specific to older people; investigating types, availability and coverage of services, cash and in-kind benefits to older people and their eligibility criteria. 
4) Primary qualitative data were collected through two main activities: 1) a 2-day 'Visioning Exercise' with the leadership team of the MoSD preceded by individual meetings and discussions; and 2) 'Prioritization Workshops' spanning over two days, in the capital of Oman (Muscat) in the summer of 2015.. The workshops involved 86 civil servants at different levels of seniority from the Omani's MoSD and MoH with large representations from service managers and directors. Based on a Theory of Change (ToC) framework, a participatory approach was adapted during the visioning exercise (Whyte, 1991). Through this exercise participants were asked to perceive the situation of various groups of the society by 2040 and reach a consensus on how social policy development could best contribute to

achieve these goals. The analysis presented here focuses on the activities related to older people. The 2-day prioritization workshops included presentations - from international experts on best practice, policies and strategies - followed by focus group discussions on how different care models and services could be best tailored to the Omani context. All discussions were recorded, transcribed and thematically analyzed through a process of familiarization, themes' identification and coding then refining (Gomm, Needham \& Bullman, 2000).

\section{Findings}

\section{Aging and Demographic Changes in Oman}

The analysis of national statistics and indicators revealed that Oman currently enjoys relatively high average life expectancy at birth (77 years), which is higher than in many Arab countries as presented in Figure 1. In 2013, female life expectancy at birth was 79 years compared to 75 years among men (World Bank [WB], 2015). However, the average life expectancy at birth in Oman was lower than that observed in Qatar and Lebanon which were 79 and 80 years respectively.

The analysis presented in Figure 1 shows that total fertility rate (TFR: the average number of children a woman would have over her reproductive life) is relatively low in Oman compared other Arab countries. This combined with a relatively high life expectancy indicates that Oman had started its second demographic transition with projected increased population aging over the coming decades than other countries in the region. Due to such trend, the relatively small proportion of older population (60 or more) standing at only four percent in 2013 is predicted to increase reach a quarter by 2050 (World Health Organization [WHO], 2015). With this projected increase and the gender gap in life expectancy at birth, it is important to note potential implications on older women in particular. Tohme and colleagues (2011) argue that older women in the region have access to fewer social support networks due to cultural gender-specific perspectives as well as gender gaps in widowhood rates and living arrangements at old age. These gender difference lead to higher proportions of older women living alone with limited access to gender acceptable activities and services. This view was supported to some extent by the findings from our study. For example, in 2010 $53 \%$ of older Omani women, aged 60 years or more, were widowed compared to only $7 \%$ of men in the same age-group (National Centre for Statistics and Information, Undated). 
Figure 1 Arab countries distributed by total fertility rate and average life expectancy (2013)

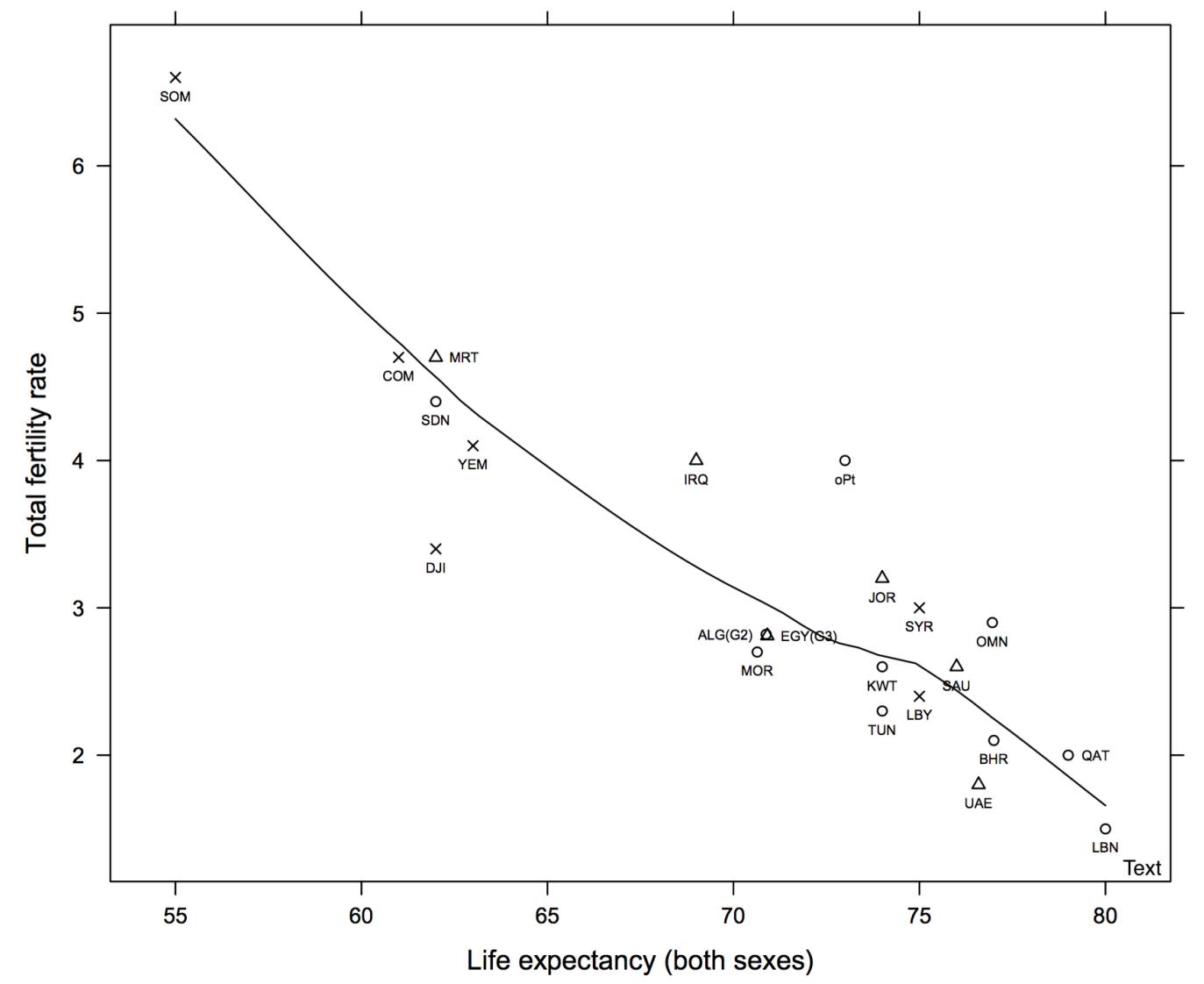

Sources: Life expectancy and fertility rates: World Bank http://data.worldbank.org/indicator; the shapes denote the level of palliative care development groups (Clark \& Wright, 2007) as following: X: No Known Activity; O: Capacity building; $\Delta$ : Localized provision

The analysis of national statistics and indicators shows that population aging is occurring within a wider context of demographic and social change including dramatic reduction in TFR in all GCC countries. Fifty years ago, TFR was stood at around seven in all GCC countries, but by the mid 1970s a big convergence started to emerge. The pace of decline in TFR, while impressive over the last three decades, had varied across countries in the region, with Oman showing one of the greatest decline - of over six children per woman of reproductive age - since 1970, leading to a projection of reach replacement level $(\mathrm{TFR}=2.1)$ between 2035 and 2050 (Sibai, Rizk \& Kronfol, 2014).

Such an aging process presents various social and financial implications at the societal and individual levels. To gain further insight into the degree of population aging and pension coverage in Oman compared to other GCC countries we gathered key statistics and related information in Table 1. The old age dependency ratio, defined as the number of persons aged 65 years and above per 100 persons between the ages of 15 to 64, measures the capacity of a working economy to sustain non-working older persons. With aging, this ratio is expected to rise in the coming decades. Table 1 indicates that Oman had one of the highest old age dependency ratios among GCCs countries exceeded only by Saudi Arabia. This and other aging indices place Oman among the group of countries with medium population aging pace alongside Saudi Arabia, while the rest of the GCC countries were considered to be experiencing population aging at a slower pace (Saxena, 2008; ESCWA, 2016). 


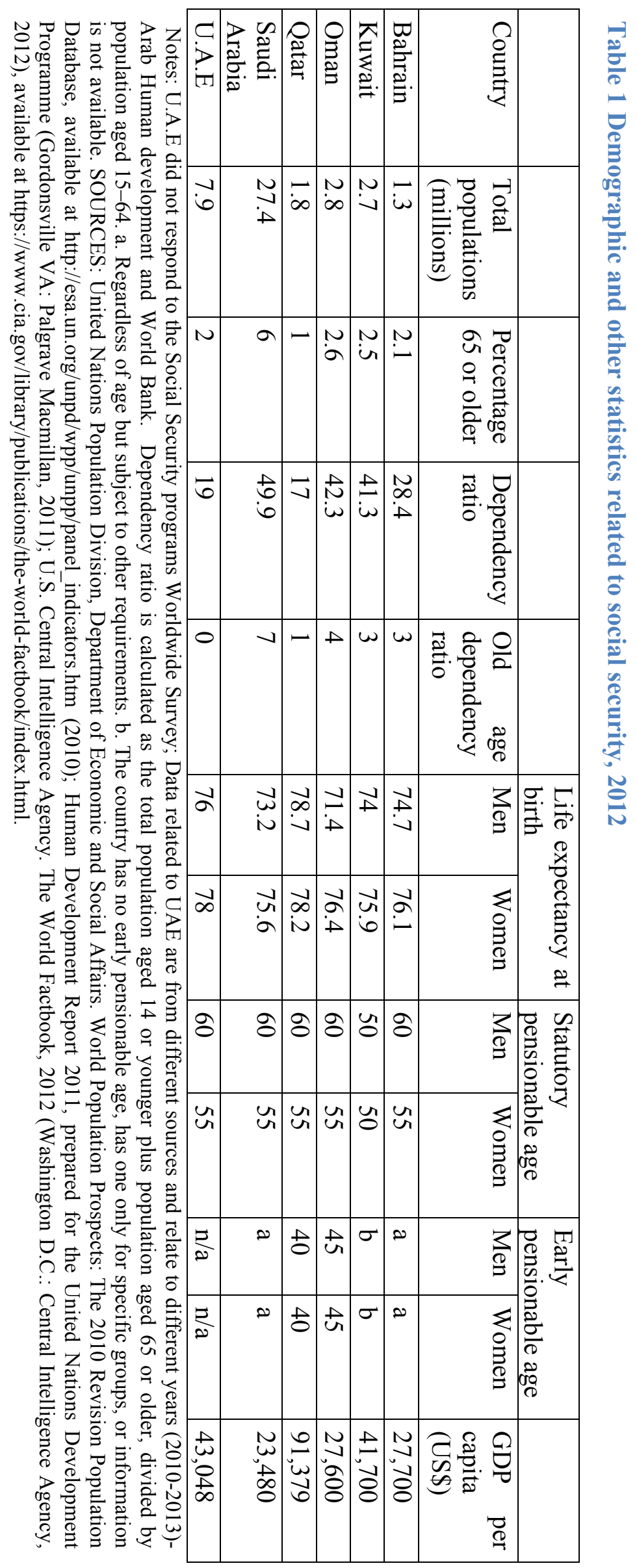


Figure 2 visualizes the results of the finite-mixture model, which identifies three groups of Arab countries according to the correlation between health expenditure per capita and life expectancy at the country level. The first cluster at the bottom left side of Figure 2, represented by solid triangles, reflected a group of countries exhibiting both low health expenditure per capita and low average life expectancy (group A). The narrow ellipse of group A indicates the similarity of the experience of this group of countries. Group A included: Djibouti; Mauritania; Somalia; Sudan and Yemen. The second group, group B, represented by solid circles in the middle of Figure 2, represent a scenario of considerable rise in life expectancy for a relatively smaller increases in health expenditure per capita in comparison to countries in group A. Group B included: Algeria; Egypt; Jordon; Iraq; Libya; Morocco; Occupied Palestinian territory; Syria and Tunisia. One clear outlier of this group is Iraq, with lower average life expectancy than all other countries of group B. The latter is likely to be associated with external factors not captured in the model, including political unrest, sanctions and wars. On the other hand, both Libya and Syria represented cases of higher life expectancy and higher or lower health expenditure per capita than group B average.

Group C, represented by squares at the top right of Figure 2, was much more dispersed than the other two groups as indicated by its wide ellipse, reflecting the uncertainty of identifying this cluster. This group included all six GCC countries along with Lebanon. Group $\mathrm{C}$ is characterized by relatively higher health expenditures per capita as well as improved average life expectancy compared to the other two groups of Arab countries. However, there are some clear outliers, particularly Lebanon where the average life expectancy is the highest in the Arab region at nearly 80 years while health expenditure per capita is much lower than the average of the GCC countries. It is not clear as why the average life expectancy in Lebanon is higher than the rest of the region but it is likely to be attributed to life style factors that were not included in the analysis.

On the other hand, within Group C, Kuwait had the highest health expenditure per capita but yet the least average life expectancy. While Kuwaiti citizens enjoy a high standard of health care compared to other countries in the region due to high level of investments in health care, yet the specific culture of Kuwait pose serious health challenges that are recognised nationally and internationally (WHO, 2014a). Studies focusing on Kuwait have shown a significant correlation between socio-cultural attitudes, lifestyles and physical activities with obesity and associated health risks. In Kuwait, type II diabetes and obesity are identified as 'emergency public health problems' by the government (Behbehani, 2014; Zaghloul et al., 2011). Figure 3 shows that while Oman belongs to the richer group C, it is one of the countries with the lowest health expenditure per capita in that group - higher only than Lebanon- yet it maintains the average life expectancy within group $\mathrm{C}$ at around 76 years. 
Figure 2 Model-based clustering for Arabic countries based on average life expetency and health expenditure per capita in each country (2013)

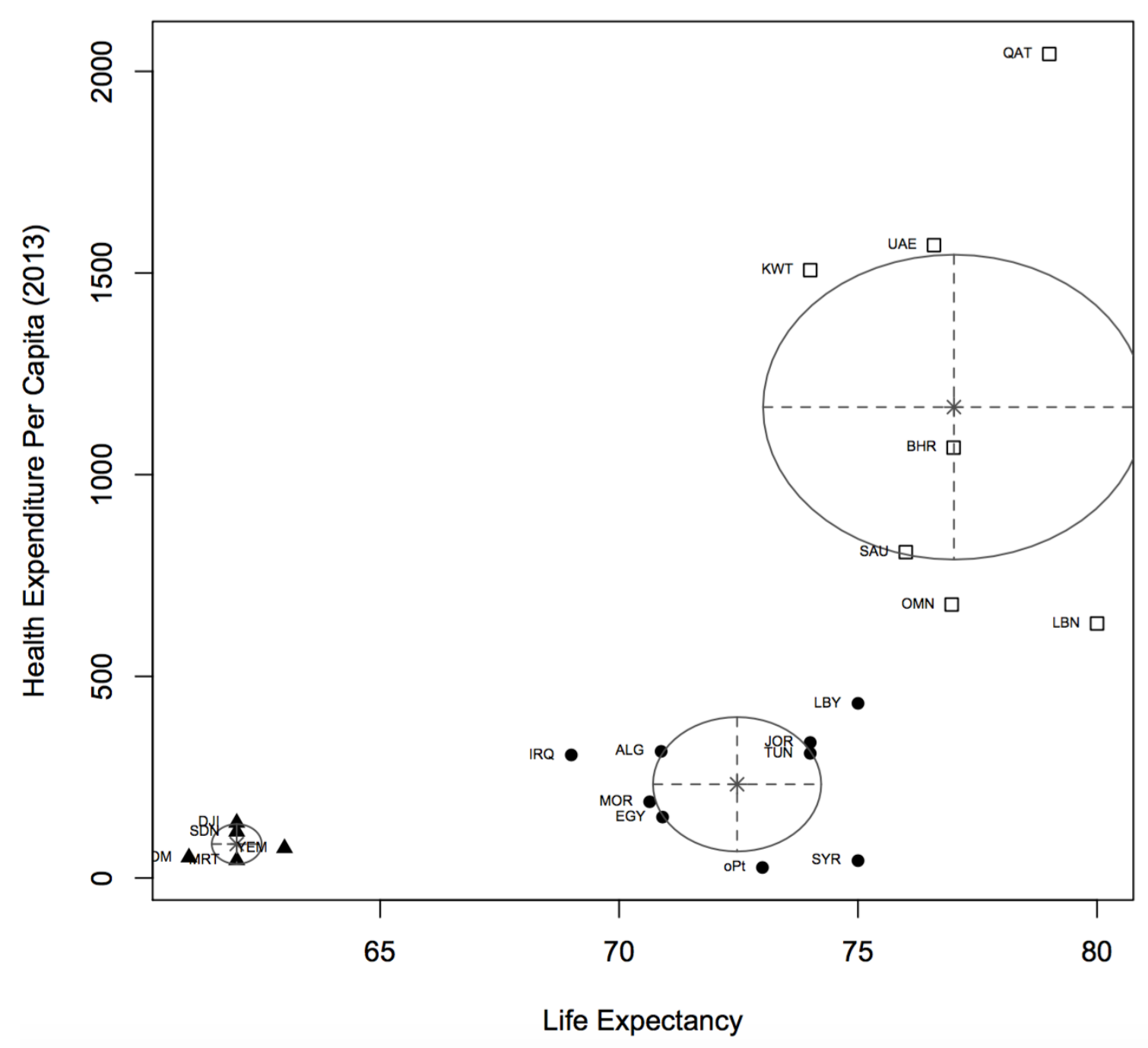

Source: Health expenditure per capita and life expectancy obtained form the World Bank statistics http://data.worldbank.org/indicator. Authors' own calculations of clusters employing a finite-mixture model.

\section{Demand for Long-Term Care Provision}

Population growth in many Arab countries creates considerable demands on the economic, social and educational infrastructures (Anderson, 2007; Hussein, 2012). Previous research indicates that changes in family structure were shown to have various implications on the wellbeing of older people (Zimmer, 2003). Within the region, the younger generations have traditionally provided LTC for older people as part of a culturally and religiously driven intergenerational support system, however this pattern had been changing quite dramatically in recent years with lower prevalence of intergenerational co-residency; higher migration rates of off-spring and unavailability of next of kin to provide LTC (Hussein \& Ismail, 2017). 
High level of morbidity including different LTC conditions that limit daily activities are observed among people aged 65 years or more in the region (Grivna et al., 2014). This is particularly true among GCC nationals where the obesity rate stood at an average of $40 \%$, one of the highest in the world (WHO, 2014b). The higher incidence of both diabetes and obesity, along with their related complications, is expected to lead to significantly higher health care costs in the next decades, especially in Bahrain, Kuwait and Oman. According to the WHO Body Mass Index (BMI) Global Database, the burden of non communicable diseases were expected to grow to a cumulative 3.9 million disability adjusted life years lost by 2025 in the Gulf region, with cardiovascular diseases being the leading cause of death (WHO, Undated). According to the Omani Ministry of Health Annual Report (2010; p. 38); the age group 60-64 had the highest rate of new diabetes diagnosis at $44.7 \%$. among all older people $(60+)$.

The analysis revealed that current official estimates of numbers of people living with disabilities in Oman were well below what is predicted by international benchmarks. Prevalence of the Omani population affected by disabilities according to national statistics was three percent in 2010 (Ministry of Social Development [MoSD], 2015), which is much lower than the World Health Organization's (WHO) estimate of 15\% (WHO, 2013). This is likely to be related to under-diagnosis, lack of awareness of invisible disabilities and lack of accurate national statistics such as 'disability registrar'. Balushi and colleagues (2011) highlighted a number of barriers people with disability face in Oman including lack of training and employment opportunities; limited capacity and ability of day centres for people with disabilities and public awareness and acceptance. The Omani Census (2010) indicated that $23.2 \%$ of people over 60 years had some form of disabilities, among them $38 \%$ with physical impairments and 35\% with visual impairments while $12 \%$ required high level of assistance with personal care. Women were reported to suffer more from physical impairments than men ( $41 \%$ vs. $36 \%)$ while men were reported to have higher prevalence of visual impairments (38\% vs. $32 \%)$.

It is worth noting that the level of schooling among older people and particularly among older women in Oman and other Arab countries is relatively low (ESCWA, 2015). Earlier studies showed that men in Arab countries gained access to education earlier and complete higher levels of education than women (Yount \& Sibai, 2009). Oman and other GCC countries were the earliest among the Arab region to establish training programs for better working opportunities for older people (Sibai, Rizk \& Kronfol, 2014). However, our study did not identify any programs that targeted older women employability.

\section{Social Security and Long-Term Care Policies}

The policy analysis and fieldwork revealed that Oman had a social insurance scheme, which was introduced in 1991. The scheme covered citizens of Oman aged 15 to 59 employed in the public and private sectors if they held permanent work contracts as well as for Omani citizens working in another GCC country. Table 2 provides details on the social insurance coverage, qualifying conditions and basic benefits. The scheme was funded through contributions from employees and employers $(6.5 \%$ and $9.5 \%$ of basic salary respectively) in addition to two percent provided by the government. Given the relatively low labour participation rate of females at 29\% in 2014 (WB, Undated), many women remained excluded from this system. 


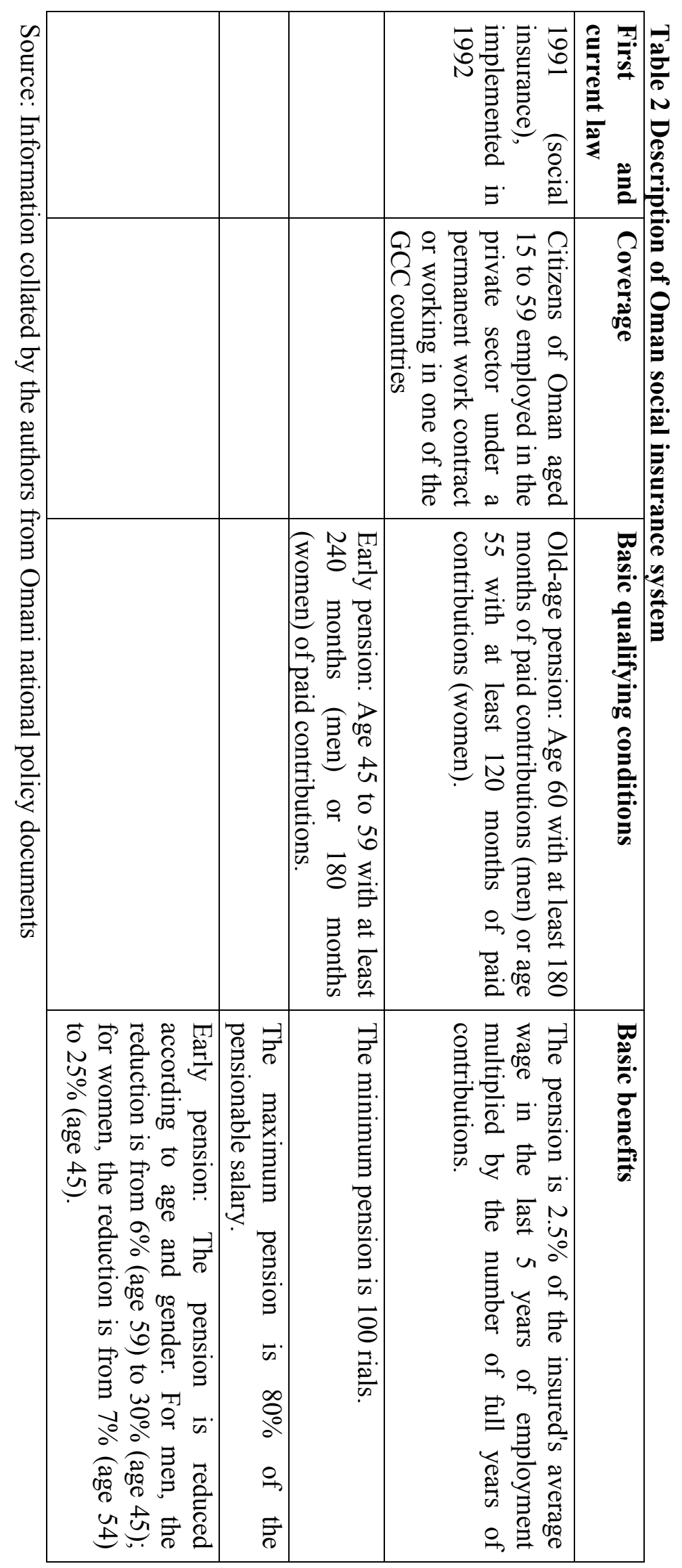


All Omani nationals have automatic access to medical care, maternity benefits, and social assistance including income-based welfare benefits. There are different levels of disability benefit available for Omani citizens. Current evidence, gathered as part of this research, indicated that the effective coverage of social insurance schemes is improving in Oman. However, social insurance schemes mainly covered pensions rather than specifically financing LTC service provisions. Furthermore, the system was fragmented with 12 separate pension funding schemes covering the private and public sectors with no overarching regulatory body.

The review of policy documents and field work indicated that Oman's LTC system was constructed around partial cash benefits that were in the main based on household income and other criteria, such as age and employment status, rather than on individual needs. These benefits were not situated within a regulated or comprehensive service structure limiting their potential impact in terms of meeting individual needs and improving people's quality of life (UNICEF, 2015). Based on the field visits and qualitative interviews it was clear that the MoSD targeted different vulnerable groups including older people, children and young people who were perceived to be at risk of harm, offending or re-offending, vulnerable women especially divorcees and people with disabilities. While there were some benefits and services to older people, these were not placed within a coherent LTC system where different services and benefits complement each other in a consistent manner. Services and initiatives included: social security (provision of cash allowances, and other privileges or subsidies, to people who have low incomes or are experiencing poverty); social care services (provision of care and support services to people in need, including juvenile justice); civil society development and regulation; and family and community development.

Figure 3 Trends in number of individuals in receipt of social benefits in Oman from 1973 to 2013, The Omani Ministry of Social Development

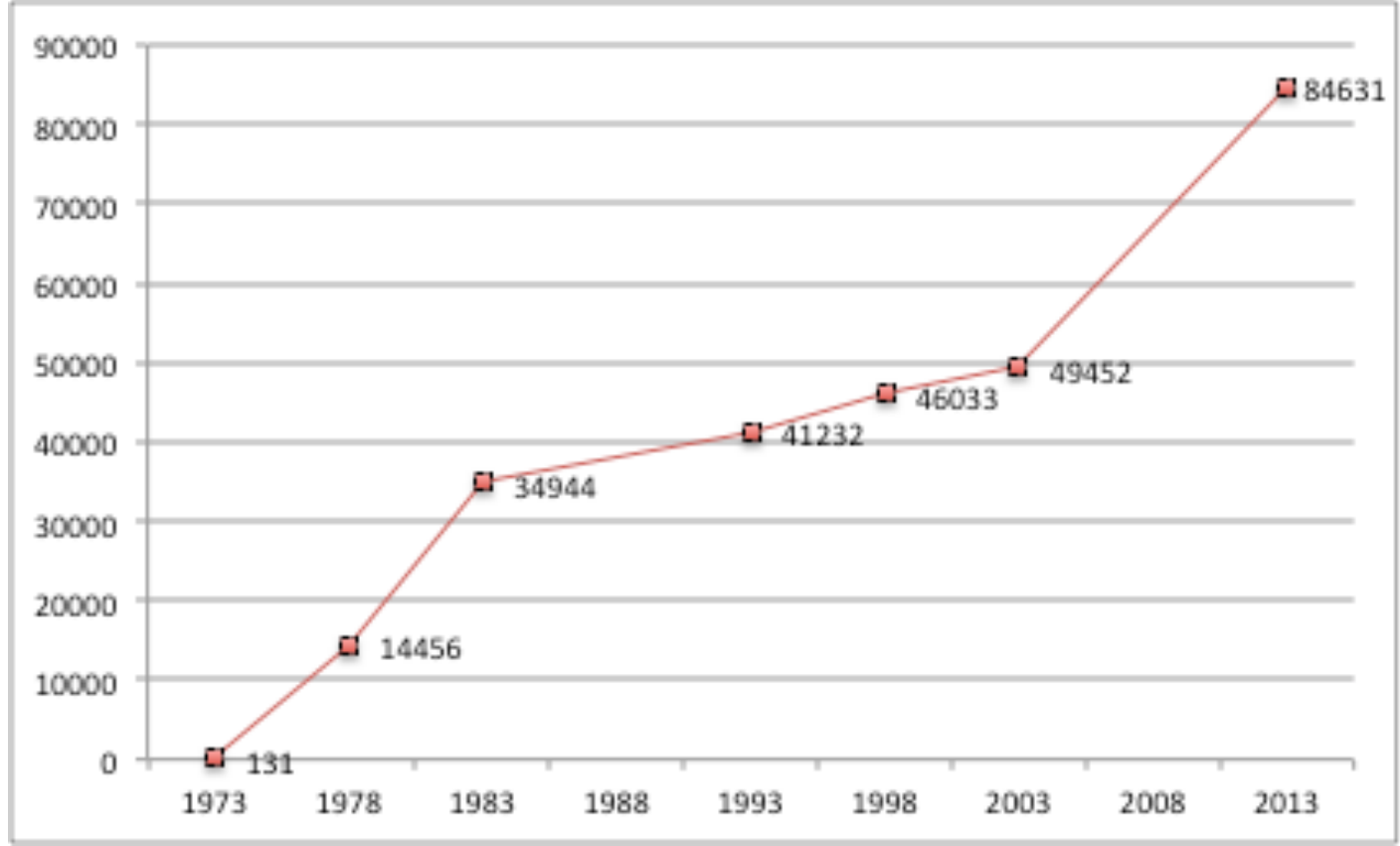

Source: Sultanate Oman Ministry of Finance, the state budget 2013-2015 
Data and trends in cash transfers in Oman show a steep increase in the number of beneficiaries, reaching nearly 85,000 in 2013. Among these cash beneficiaries, $39 \%$ related to pensions and old age benefits while the remaining covered income-related benefits, disability benefits and emergency funds including those for single mothers. The amount of individual benefits had also increased in nominal terms (MoSD, 2015). Figure 3 presents the trend of social benefits' coverage in Oman since 1973 showing a dramatic increase of the number of individuals in receipt of social benefits particularly in the decade from 2003-2013.

\section{Financing Long-Term Care}

The evidence review indicated that health and LTC provisions in Oman were predominantly financed by the government. In 2006, the government-share in health expenditure was $80 \%$, while private sector share was about $17 \%$, of which private out-ofpocket expenditure was just $9 \%$ and the remaining $3 \%$ were covered by charitable and the not-for-profit sector (WHO, 2006). Since 2006, insurance reforms in some GCC countries had led to an increased importance of the private sector's share in meeting the growing demand for health and LTC services. However, in 2014, the health expenditure remained mostly funded by the government, with the public sector covering around $75 \%$ of total health expenditure in the region (EYGM, 2016).

Figure 4 Health, Education and Social Development Expenditure as a percentage of Gross Domestic Product (GDP) in Oman, 2013-15

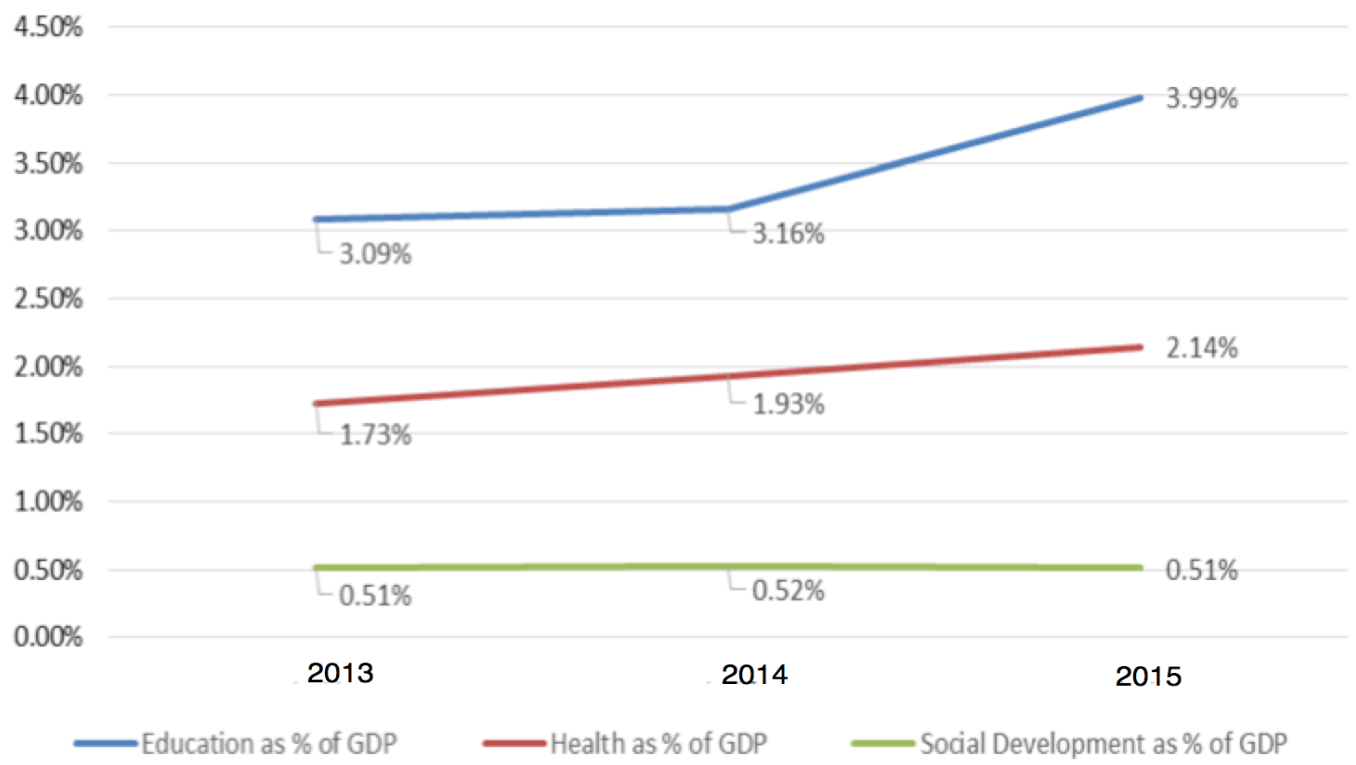

Source: Sultanate Oman Ministry of Finance, the state budget 2013-2015

Figure 4 presents trends in health, education and social development expenditures as percentage of GDP from 2013-15 in Oman based on data obtained from the national statistics and policy documents. Social development expenditures cover all spending related to LTC benefits and services in Oman. It is clear from Figure 4 that Oman had increased its 
expenditure on education and to a lesser extent on health, however, expenditures on social development as a percentage of GDP remained almost constant, between 2013 and 2015, at less than one percent.

Figure 5 shows that in Oman the percentage of expenditure on social development, which included all social care support, of total public expenditure had slightly declined from $3.8 \%$ in 2013 to $3.2 \%$ in 2015 . On the other hand, the corresponding percentage for health expenditure had increased over the same period of time from $12.8 \%$ to $13.6 \%$. It is worth noting that in 2013 a home-based health care support scheme for older people, and people with LTC needs, was established in Oman. This scheme was funded and regulated by the $\mathrm{MoH}$; thus some of the health expenditures during this period might relate to LTC services' provision.

Figure 5 Expenditures on social development, education and health as a percentage of total public expenditure in Oman, 2013-15

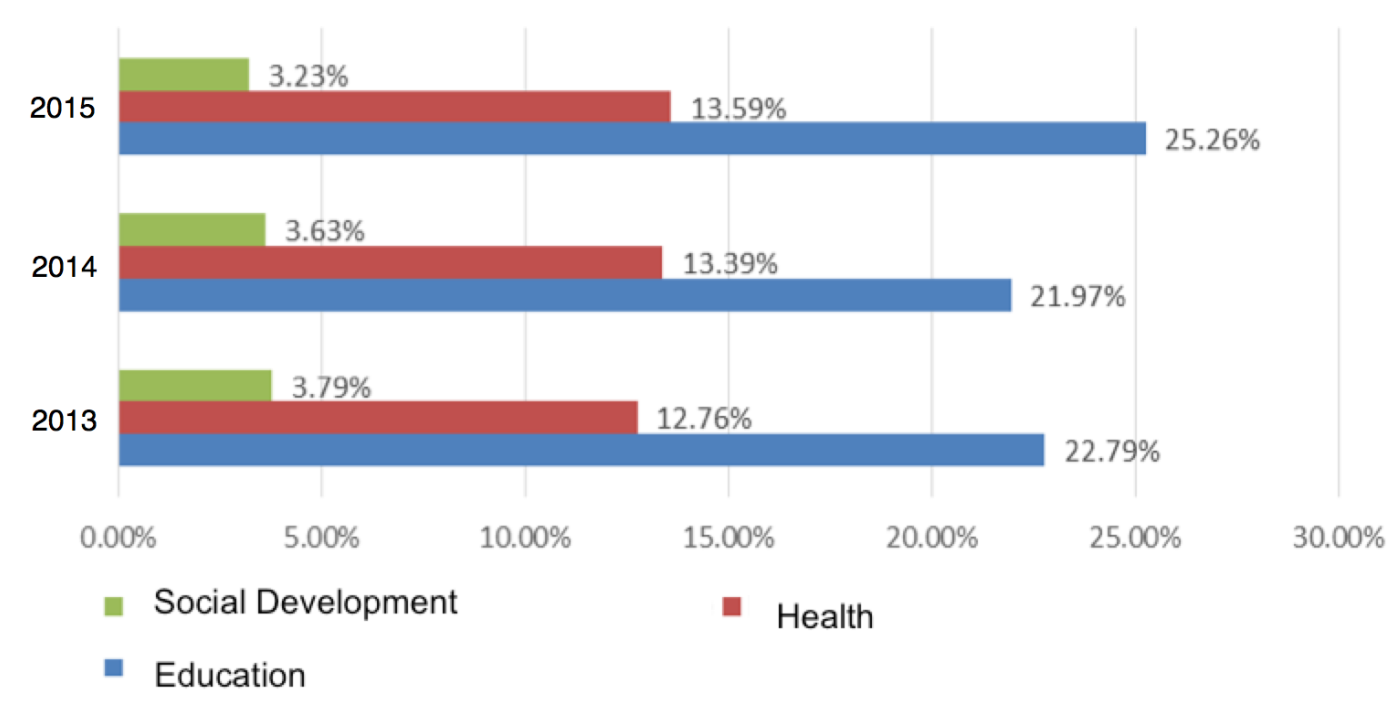

Source: Sultanate Oman Ministry of Finance, the state budget 2013-2015

\section{Discussion}

\section{Limitations of the study}

The current study benefited from rarely available information from the Ministry of Health and Ministry of Social Development in Oman. It also made use of available national and international indicators of aging and LTC in the region. However, such indicators are limited for most countries and in particular for the Arab region. The scoping literature review identified limited relevant publications that directly address aging and LTC in the region in general and in Oman in particular. Furthermore, this study had limited access to the direct perspectives of older people and their relatives in Oman.

The current analyses reveal the challenges facing all GCC countries in relation to population ageing and changing demographic and societal structures. Oman enjoys a relatively high average life expectancy at birth of 77 , which is higher than the majority of the 
Arab region, with the percentage of population aged 60 years or more projected to reach $24.5 \%$ by 2050 . Yet, even in countries such as Oman with high GDP per capita, the findings point to limited services and programs specific to LTC among older people. Oman's current LTC structure, which is based mainly on concepts of intergenerational solidarity, faces various challenges that are associated with broader demographic and societal changes within the families and across the society. There are also other challenges related to wider macro economic factors, for example, much of Oman's economic and social progress has been enabled by the sustained period of high oil prices, however, there is no guarantee that such a historical period will be repeated. Thus future sources of funding for health expenditures in general, and LTC in particular, needs to be established and protected to match the projected escalating demands related to population-aging and changes in the social and demographic structures.

The analyses presented here highlight the vulnerable position of older people particularly women within the cultural context of Oman and many other GCC countries. These do not only relate to gender gaps in life expectancy but also to gender gaps in income (in)security, rates of widowhood at old age, burden of disease at old age, and level of reliance on intergenerational solidarity as a key mechanism of LTC support. The latter is particularly problematic, as it does not acknowledge the changing demographic and societal landscape where women, at the labour market participation age groups, are under enormous work and multiple caring burdens. Demographic changes and rapid urbanization are already bringing new forms of household structures within the Omani family. Previous marriage patterns traditionally observed in the Arab countries- characterized by women's early marriage, universality of marriage for both sexes and large age differences between spouses- have been changing greatly in many respects during the past few decades (Hussein, 2002; Hussein \& Manthorpe, 2007; Rashad, 2015). These intertwined developments call for an urgent need to consider a new model of LTC in the region, which ought to capitalize on the embedded cultural norms of solidarity while offering alternative culturally-sensitive services and programs. Such new model is required to be gender-sensitive to address the current and projected gaps in services' availability and access to older women.

The findings obtained from the finite-mixture model strongly suggest that health expenditure per capita is not the only factor in improving health outcomes including the average life expectancy. Countries like Lebanon, with modest health expenditure in comparison to most GCC countries, enjoy a much higher average life expectancy. Furthermore, the literature suggests a significant impact of life style on life expectancy and quality of life at later age. This is particularly important in relation to the observed high prevalence of obesity and diabetes in GCC countries. Here, policies related to active aging, healthy life styles and independent ageing should be developed with parallel adequate investments in services and support mechanisms to older people and their families.

The current analyses attempted to make use of available national statistics and indicators of aging in the region. The review indicated serious shortcomings in terms of basic indicators relevant to LTC needs and services that are specific to the region. For example, it was not possible to understand the experience of older people and how they felt their needs are met and to investigate important issues such as quality of life, loneliness, social inclusion or safeguarding from older people's perspective due to lack of data and indicators. Thus, there is a strong need to develop a set of indicators that captures the ageing process in a systematic and comprehensive manner and to promote the recording and use of data for analysis. It is equally important to use data and evidence to systematically monitor and 
evaluate services and programs across various governmental bodies within an integrated structure.

In 2015 the Omani MoSD has developed a 10-year Strategy on Social Development (2016-2025), which details a new model for LTC benefits and services. This strategy was regarded to represent a milestone in developing strategies specific to different 'vulnerable' population groups including older people and those with long term care needs. The vision within the strategy strongly refers to the importance of the family as the basis of society, to religious principles, justice, equality and fairness. This strategy emphasized the transition from 'the philosophy of providing services to the philosophy of the quality of services through the adoption of results-based management approach, and to develop a comprehensive framework for quality based on clear strategic objectives service' (MOSD, 2015: p. 3). Such recent policy developments in LTC policies in Oman reflect broader attention to aging issues in some Arab and GCC countries. Findings from the workshops indicated a need to increase public awareness of issues related to aging and long term disabilities and to build effective partnerships between governmental departments and across various actors including the private (for-profit) business, civil societies and individual citizens and their families to address the projected escalating demands.

While there seems to be very recent promising developments in recognizing issues related to aging in Oman there remains a lack of clear national strategy of action on how to accommodate the specific needs of older people and enable them to live independently. Similarly, there is no clear evidence of securing relevant fiscal envelop to ensure such developments nor there are indications of the implementations of recent policies into practice.

\section{Conclusion}

Population aging is a phenomena occurring across the globe including in countries traditionally exhibiting population dividends and 'youth bulges' such as Arab and Gulf countries. Focusing on Oman as a case study of the Gulf region, it is clear the process of population aging is fast occurring. These aging dynamics are occurring within a cultural context of the family as the central care provider, however, this very context is challenged through parallel socio-demographic changes. Oman, similar to many other Arab countries, places the family as the central foci of its social policy structure including that related to old age. Recent policy developments in Oman indicate the start of an attention-shifting process to long-term care, yet spending on LTC, infrastructure of services and general awareness of issues related to aging are still in their infancy. However, the implementation of this strategy has not started yet and it would be useful to examine practical challenges and successes of such approach as it is rolled out in the future. 


\section{References}

Ahmed, N. I., \& Abbas S. (1993). Family care of elderly problems. Journal of the Egyptian Public Health Association, 68, 161-177.

Al-Kandari, Y., \& Crews, D. (2014). Social support and health among elderly Kuwaitis. Journal of Biosocial Science, 46, 518-530.

Anderson, C.G. (2007). The Sultanate of Oman's Foreign Policy: An Assessment of Pre and Post 9/11 Developments. Asian Profile, 35,11-20.

Balushi, T., Al-Badi, A \& Saqib, A. (2011). Prevalence of Disability in Oman: Statistics and Challenges. Canadian Journal of Applied Sciences, 1, 81-96.

Behbehani, K. (2014). Kuwait National Programme for Healthy Living: First 5-Year Plan (2013-2017). Medical Principles and Practice, 23, 32-42.

Drysdale, A. (2010). Population dynamics and birth spacing in Oman. International Journal of Middle East Studies, 42, 123-144.

EYGM. (2016). Investment big bets: Health care and life sciences in the GCC. EY Building a better working world. Retrieved from:

http://www.ey.com/Publication/vwLUAssets/EY-investment-big-bets-healthcare-tlreport/\$FILE/EY-investment-big-bets-healthcare-tl-report.pdf

Fraley, C. \& Raftery, A. E. (2002). Model-based clustering, discriminant analysis, and density estimation. Journal of the American Statistical Association, 97, 611-631.

Grivna, A., Eid, H. \& Abu-Zidan, F. (2014). Epidemiology, morbidity and mortality from fall-related injuries in the United Arab Emirates. Scandinavian Journal of Trauma, Resuscitation and Emergency Medicine, 22:51.

Hussein S. (2009). The role of women in long-term care provision: Perspectives on aging in the Arab and Islamic world. Paper presentation, $10^{\text {th }}$ Islamic Countries Conference on Statistical Sciences (ICCS-X), Cairo: 20-23 December 2009.

Hussein, S. (2002). An Exploration of Nuptiality Patterns in Egypt and the Maghreb Countries. PhD Thesis, London School of Economics: London.

Hussein, S. (2012). Long-term care services, workforce and skills needs: How can the Arab region prepare for the ageing population demand using data and existing research? $12^{\text {th }}$ Islamic Countries Conference on Statistical Sciences, 19-22 December, Doha, Qatar.

Hussein, S. \& Ismail, M. (2017). Ageing and Elderly Care in the Arab Region: Policy Challenges and Opportunities. Ageing International. 2(3): 274-289.

Hussein, S. \& Manthorpe J. (2007). Women from the Middle East and North Africa in Europe: understanding their marriage and family dynamics. European Journal of Social Work, 10(4) 465-480.

Jarallah, J. S., \& Al-Shammari, S. (1999). Factors associated with health perception of Saudi elderly. Journal of Cross-Cultural Gerontology, 14, 323-334.

Khan, H., Hussein, S. \& Deane, J. (2017). Nexus between demographic change and elderly care need in Gulf Cooperation Council (GCC) Countries: Some policy implications. Ageing International, 42 (4):466-487.

National Centre for Statistics and Information. (Undated). Retrieved from: https://www.ncsi.gov.om/Pages/NCSI.aspx

Olmsted, J. (2011). Norms, economic conditions and household formation: A case study of the Arab world. The History of the Family, 16, 401-415.

Rashad, H. (2015). The tempo and intensity of marriage in the Arab region: Key challenges and their implications. Social Research Center, American University in Cairo:

Cairo. 
R Core Team (2017). R: A language and environment for statistical computing. R Foundation for Statistical Computing, Vienna, Austria. URL https://www.R-project.org/.

Rugh, A. B. (1997). Within the circle: parents and children in an Arab village. New York, Columbia University Press.

Saxena, P. C. (2008). Ageing and age-structural transition in the Arab countries: regional variations, socioeconomic consequences and social security. GENUS, 37-74.

Seoud, J., Nehme, C., Atallah, R., Zablit, C., Yeretzian, J., Levesque, L...\& Ducharme, F. (2007). The health of family caregivers of older impaired persons in Lebanon: An interview survey. International Journal of Nursing Studies, 44, 259-272.

Sibai, A.M., Rizk, A., \& Kronfol, K.M. (2014). Ageing in the Arab Region: Trends, Implications and Policy options. The United Nations Population Fund (UNFPA), Economic and Social Commission of Western Asia (ESCWA) and the Center for Studies on Aging (CSA): Beirut.

Sultanate Oman Ministry of Social Development [MoSD]. (2015). Sultanate Oman Strategy for Social Development 2016-2025. Produced in collaboration with UNICEF, Alexander, G., Hussein, S., AbdulJawad, M., Hussein, L., Adawi, I., Zakaria, K. ... \&nd Yali, V. Muscat: Ministry of Social Development. [In Arabic]

Tohme, R., Yount, K., Yassine, S., Shideed, O. and Sibai, A. (2011). Socioeconomic resources and living arrangements of older adults in Lebanon: who chooses to live alone? Ageing and Society, 31(1): 1-17.

UNICEF. (2015). Oman Social Development Strategy: Diagnostic Study Report. May 2015. UNICEF and Ministry of Social Development: Muscat. [In Arabic]

United Nations. (2015). World Population Ageing. Retrieved from: http://www.un.org/en/development/desa/population/publications/pdf/ageing/WPA20 15_Report.pdf

World Health Organization [WHO]. (2006). Obesity and overweight. Fact Sheet No. 311. Retrieved from: http://www.who.int/mediacentre/factsheets/fs311/en/index.html.

WHO. (2014a). Country Cooperation Strategy for WHO and Kuwait 2012-2016. World Health Organization, WHO-EM/PME/005/E/02.14.

WHO. (2014b). Non-communicable Diseases (NCD) Country Profiles.

WHO. (2015). Oman: WHO statistical profile. Retrieved from http://www.who.int/gho/countries/omn.pdf?ua=1

WHO. (undated). Global Database on Body Mass Index: An interactive surveillance tool for monitoring nutrition transition. Retrieved from: http://apps.who.int/bmi/

Whyte, W. F. (Ed.). (1991). Sage focus editions, Vol. 123. Participatory action research. Thousand Oaks, CA: Sage Publications.

World Bank. (2015). World Bank micro data. Retrieved from:

http://data.worldbank.org/indicator/SP.DYN.LE00.MA.IN

Yount, K. M. \& Sibai, A.M. (2009). Demography of Aging in Arab Countries. In Poston, D.L. \& Uhlenberg., P. (Eds.), International Handbook of Population Aging. (pp. 277-315). Springer: Netherlands.

Yount, K. M. \& Rashad, H. (2008). Family in the Middle East: ideational change in Egypt, Iran and Tunisia. London: Routledge.

Zaghloul, S., Harrison, G. \& Popkin, B. (2011). The prevalence and trends of overweight, obesity and nutrition-related non-communicable diseases in the Arabian Gulf States. Obesity Review, 12, 1-13.

Zimmer, Z. (2003). Family Size and Support of Older Adults in Urban and Rural China: Current Effects and Future Implications. Demography, 40, 23-44. 
Notes:

${ }^{1}$ Saudi Arabia, Kuwait, the United Arab Emirates, Qatar, Bahrain, and Oman. The GCC was established in Riyadh, Saudi Arabia, in May 1981

${ }^{2}$ Algeria, Bahrain, the Comoros Islands, Djibouti, Egypt, Iraq, Jordan, Kuwait, Lebanon, Libya, Morocco, Mauritania, Oman, Palestine, Qatar, Saudi Arabia, Somalia, Sudan, Syria, Tunisia, the United Arab Emirates, and Yemen 